\title{
Using Medicinal Plants to Improve the Health of the Population in Russia
}

\author{
I.B. Kirina ${ }^{1, *}$, Yu.V. Trunov ${ }^{1}$, E.N. Tretyakova ${ }^{1}$, A.Yu. Medelyaeva ${ }^{1}$, N.N. \\ Chesnokov $^{1}$ and O.A. Rudaya ${ }^{1}$ \\ ${ }^{1}$ Michurinsk State Agrarian University, 101, International st., Michurinsk, 393760, Russia \\ *Corresponding author. Email: kirina@mgau.ru
}

\begin{abstract}
Fruits and vegetables are a valuable source of biologically active substances (vitamins, mineral salts, P-active substances, fiber, pectin and other vital ingredients). Currently, a huge number of varieties with a set of economically valuable features have been created for industrial and amateur gardening. A modern consumer shows an increased interest in the quality of products, including the abundance of biochemical composition, therapeutic and preventive properties. In the middle of the twentieth century, a new direction of "medical gardening" was established in horticulture, which underwent both rapid development and decline. Currently, medical horticulture in Russia is developing efficiently. The paper identifies crops which fruits have high antioxidant activity. The following varieties with an increased content of biologically active substances are recommended for planting in a medical garden in the Central Chernozem Region: Fragaria $\times$ ananassa - Privlekatelnaya, Urogaynaya CGL, Fireworks, Rubus idaeus L. Balsam, Heracles, Eurasia, Zolotaya Osen, Kokinskaya; Ribes nigrum - Nara, Odzhebin, Orlovskaya serenada, Selechinskaya, Exotica; Hippophae rhamnoides - Novost Altaya, Pride of CGL, Krasnoplodnaya, Kudyrga, Shcherbinka; Sorbus aucuparia L. - Angri, Alaya krupnaya, Sorbinka, Burka, Moravskaya; Viburnum opulus L. Akkord, Zagadka, Zorina, Luch, Elexir; Lonicera edulis L. - Berel, Galochka, Kamchadalka, Pushkinskaya; Vaccinium corymbosum - Gerbert, Kovill.
\end{abstract}

Keywords: medicinal plants, population health, biologically active substances, medical garden

\section{INTRODUCTION}

Fruits and vegetables are an indispensable source of natural biologically active substances (BAS), which include vitamins, minerals, phenolic compounds, antioxidants, tannins and aromatic substances, fiber, etc. Due to rich biochemical composition, fruits and berries have therapeutic and preventive properties.

For the normal life of the human body, the annual need for fresh fruits and berries is $90-100 \mathrm{~kg}$ per person. The actual consumption of this type of food in Russia is about $50-55 \mathrm{~kg}$ : $35 \mathrm{~kg}$ of them are imported products and only $15-20 \mathrm{~kg}$ are domestic products [8]. In this regard, the population of the country is experiencing an acute shortage of domestic fresh fruits. This problem has been particularly relevant in recent years under the conditions of sanctions and the need for import substitution.

The number of products primarily depends on the efficiency of development of the industry. Low efficiency of domestic horticulture is caused by numerous agroecological and socio-economic problems that have an impact on the development of the industry.

Initially, the development of horticulture in the country was characterized by the concentration of large fruit and berry plantations in the farms of landowners and at monasteries. In modern conditions there is the world trend of transition from extensive horticulture to intensive types of gardens with high planting density on clonal rootstock $[1,9]$. 
A modern consumer shows an increased interest not only in the quality of products, but also in the abundance of biochemical composition, therapeutic and preventive properties. In this regard, it became necessary to breed varieties with an increased content of biologically active substances and grow them in industrial plantations and on household plots.

The purpose of the study was to consider the peculiarities of formation and modern state of "medical horticulture" in Russia.

\section{MATERIALS AND METHODS}

The study was performed in 2005-2020 at Michurinsk State Agrarian University. The objects of study included such varieties as Fragaria $\times$ ananassa, Rúbus idaeus, Ribes nigrum, Hippophaë rhamnoides, Sorbus aucuparia L., Viburnum opulus L., Lonicera edulis L., Vaccinium corymbosum; Rosa.

The content of biologically active substances in fruits was determined during the period of harvest maturity according to generally accepted methods [7].

\section{RESULTS AND DISCUSSION}

The vegetable kingdom is rich and diverse. Herbal treatment has always attracted human attention and is closely interlinked with the development of the human body. The achievements of Tibetan, Indian, ancient Roman, Arabic medicine are widely known.

What are the prerequisites that contributed to the formation of "medical horticulture" in Russia?

In Ancient Russia, clergy, as well as folk healers witch doctors, wisewomen - have long been engaged in herbal treatment. In the IX-X centuries, information about medicinal herbs and their therapeutic use penetrated from other countries into Kievan Rus. In the XI century, monasteries were built everywhere, which focused on healing, cultivation, collection and procurement of medicinal plant raw materials. In church books there is a mention of "healers" - people who treated patients and distributed handwritten herbals, books of home cures, etc. Already in those days it was believed that fresh plants help better, so fruits, vegetables, greens were prescribed to a patient in a "rough" (raw) form. Plant food was recommended to eat more than any other type of food.

In the XVI century, the first pharmacy was created in Moscow to treat the royal family, in which foreign doctors served. Under Ivan the Terrible (1581), the Pharmacy Hut was founded, which controlled the collection of wild medicinal raw materials in Russia. At the end of the XVI century, the Pharmacy Hut was transformed into the "Pharmacy Order" with dryers, warehouses, pharmacies and other premises. The pharmacy order attracted wide segments of the population: herbalists, peasants, Cossacks, artisans and their children. Doctors and pharmacists from the order managed the collection and processing of medicinal plants on the spot. In the middle of the XVII century, the Pharmacy Order served the royal family, troops, and also controlled the collection, search and breeding of new medicinal plants. It should be noted that already at that time, doctors drew attention to the healing benefits of not only wild medicinal herbs, but also highlighted the beneficial properties of fruit and vegetable plants. Rosehips were used to treat the wounded and patients with scurvy during military campaigns. Medicinal qualities of onions and garlic were widely used [4].

In the second half of the XVII century the Izmailovsky Gardens were created by the decree of Tsar Alexei Mikhailovich, in which food, medicinal and ornamental plants were grown. At the beginning of the XVIII century apothecary gardens were created in all large cities at military hospitals and monasteries by the order of Peter the Great (Fig. 1).

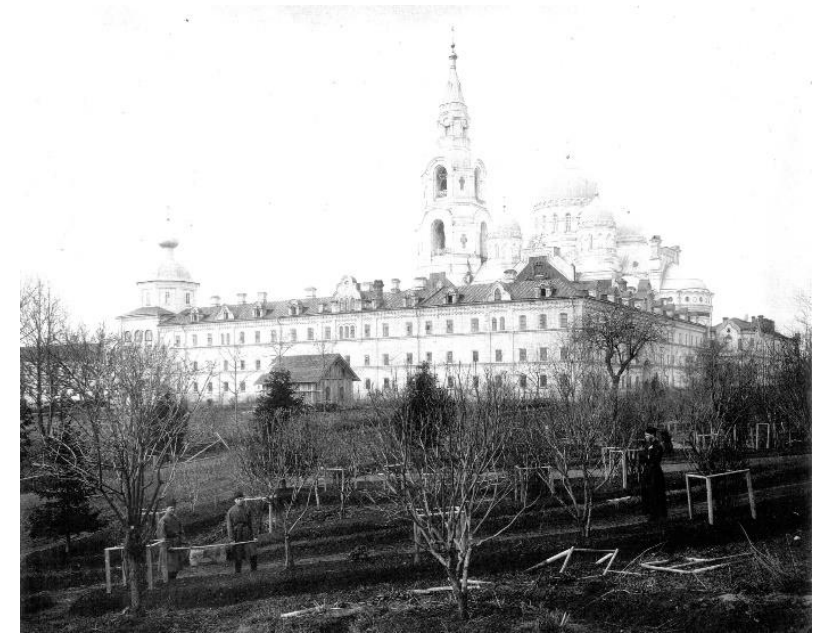

Figure 1. Apothecary garden in Valaam village

The XIX-XX centuries are characterized by the development of fruit growing, vegetable growing, and crop growing. Industrial gardens and household plots are laid throughout the country. Breeder scientists in scientific institutions breed new varieties, expand the range of varieties.

I.V. Michurin paid great attention to the biochemical composition of fruits and berries, noting: "I also pay attention to the possibility of getting varieties which consumption will contribute to the treatment of certain diseases". In order the population benefits from plant products enriched with biologically active substances, the scientist was interested in such minor crops as Rosa L., Lonicera L., Actinidia, Aronia melanocarpa (Michx.) Elliot., Amelanchier, (Chaenomeles Maulei (Mast.) C. K. Schneid.). Ivan Vladimirovich 
recommended these species for introduction into culture.

The first garden of medical crops laid in 1950 in Russia at Ural Forestry Institute played a special role in the development of medical gardening. In 1956, a laboratory of biologically active substances was established under the direction of L.I. Vigorov [5, 12]. The detection of a set of biologically active substances in fruits and berries allows them to be used not only for food purposes, but also for the protection of the human body from pesticides, radioactive elements, for the prevention of various diseases (cardiovascular, nervous, inflammatory, etc.). Due to the work of scientists and the promotion of domestic medical gardening, specialized horticultural state farms were created in the northern region, as well as medical crop gardens at schools, kindergartens, hospitals. Amelanchier, Chaenomeles Maulei (Mast.) C. K. Schneid., Lonicera L., Hippophae rhamnoides, Crataegus, Berberis vulgaris L., Ribes nigrum, Malus L. were grown in such plantations. Fresh fruits and their processed products (juices, jams, fruit paste, dried fruits) entered the retail chain in specialized stores called "Medicinal Fruits". Crops that prevent anaemia, gastrointestinal diseases, preserve vision in children, prevent muscle dystrophy, and heart disease were grown in school gardens [2]. Experiments in the field of environmental recovery are particularly interesting among the studies of the Ural Garden due to aerofolins (volatile substances) [9].

In 2020, the garden turned 70 years old. The collection contains more than 300 species. Among the main tasks of the Ural Garden of Medical Cultures named after Professor L.I. Vigorov is the preservation of a complex heritage for future generations.

The experience of the northern region contributed to the development of medical gardening throughout the country. Biochemists and breeders of the Oryol Fruit and Berry Experimental Station (1968) launched a program to study and identify valuable source varieties of Malus. Domestica, Ribes nigrum, create a hybrid fund and select elite seedlings with an increased content of vitamin $\mathrm{C}$, soluble solids and a harmonious combination of sugar and acid. At the moment, one of the priority areas of the All-Russian Research Institute for Fruit Crops Selection (Oryol) is the selection for improved biochemical composition and taste qualities of garden fruits.

The years of perestroika are characterized by a decline in the state of gardening in general and medical gardening in particular. The "revival" of medical gardening was noted at the beginning of the XX century. However, it is mainly concentrated in the farms of amateur gardeners, farmers.

The integration with pharmaceutical companies in the southern regions of Siberia contributed to the development of medical gardening. Pharmaceutical, perfume and cosmetic industries are actively developing that mainly make products using sea buckthorn oil and rosehips oil.

Scientific institutions in Michurinsk also played a special role in the development of medical gardening. The biochemical composition of the collection fund of garden and minor crops of local selection and introduced varieties is assessed at I.V. Michurin Federal Research Center, Michurinsk State Agrarian University. Particular attention is paid to the content of biologically active substances, many of which, including antioxidants and antiradiants, increase resistance to stressors and environmental pollution.

Table 1 shows the average long-term data on the content of biologically active substances and antioxidant activity in terms of dihydroquercetin contained in the fruits of berry and minor crops of the Central Chernozem Region.

Table 1. Average long-term BAS content in the fruits of berry and minor crops

\begin{tabular}{|l|l|l|l|}
\hline Culture, variety & $\begin{array}{l}\text { Ascorbic } \\
\text { acid, } \\
\mathrm{mg} / 100 \mathrm{~g}\end{array}$ & $\begin{array}{l}\text { P-active } \\
\text { substances, } \\
\mathrm{mg} / 100 \mathrm{~g}\end{array}$ & $\begin{array}{l}\text { Antioxidant } \\
\text { activity, } \\
\mathrm{mg} / 100 \mathrm{~g}\end{array}$ \\
\hline $\begin{array}{l}\text { Fragaria } \times \\
\text { ananassa L. }\end{array}$ & 59.2 & $190-320$ & 260.2 \\
\hline Rubus idaeus L. & 36.5 & $80-350$ & 340.5 \\
\hline Ribes nigrum L. & 160.0 & $450-580$ & 405.5 \\
\hline $\begin{array}{l}\text { Vaccinium } \\
\text { corymbosum L. }\end{array}$ & 18.8 & $300-1800$ & 400.0 \\
\hline Lonicera edulis $\mathrm{L}$. & 25.6 & $1600-3500$ & 420.4 \\
\hline
\end{tabular}

The berries of Ribes nigrum L. act as sources of ascorbic acid. The fruits of Vaccinium corymbosum L., Lonicera edulis L. are characterized by high content of P-active substances (anthocyans, catechins). The berries of Ribes nigrum L., Vaccinium corymbosum L., Lonicera edulis L. are recommended as a source of antiradiants.

The multi-year research made it possible to identify varieties with an increased content of ascorbic acid, carotene, pectin, P-active compounds: Fragaria $\times$ ananassa - Privlekatelnaya, Urogaynaya CGL, Fireworks, Rubus idaeus L. - Balsam, Heracles, Eurasia, Zolotaya Osen, Kokinskaya; Ribes nigrum Nara, Odzhebin, Orlovskaya serenada, Selechinskaya, Exotica; Hippophae rhamnoides - Novost Altaya, Pride of CGL, Krasnoplodnaya, Kudyrga, Shcherbinka; Sorbus aucuparia L. - Angri, Alaya krupnaya, Sorbinka, Burka, Moravskaya; Viburnum opulus L. - Akkord, Zagadka, Zorina, Luch, Elexir; Lonicera edulis L. - 
Berel, Galochka, Kamchadalka, Pushkinskaya; Vaccinium corymbosum - Gerbert, Kovill [3, 7, 8].

The educational and research laboratory of functional food products, the educational laboratory for preserving fruits and vegetables of Michurinsk State Agrarian University develop technologies for the production of functional and dietary products from fruits and berries with an increased content of pectins, vitamin C, phenols, etc. [11].

\section{CONCLUSION}

Thus, in the conditions of deterioration of the environmental situation and weakening of public health in Russia it is necessary to expand the areas for intensive and medicinal gardens, increase the yield of planting material of garden crops and varieties with high content of biologically active substances.

\section{REFERENCES}

[1] L.A. Velibekova, M-R.A. Kaziyev, G.D. Dogeev, The Problems of Introducing Innovative Technologies in Industrial Gardening in Dagestan, Stud. in Syst., Decis. and Contr. 282 (2020) 307314.

[2] J.R.F.W. Leuven, A.H.M. Rutenfrans, A.G. Dolfing, R.S.E.W. Leuven, School gardening increases knowledge of primary school children on edible plants and preference for vegetables, Food Sci. and Nutrit. 6(7) (2018) 1960-1967.

[3] I.B. Kirina, E.V. Shchekochikhina, Biochemical value of fruits of black currants and northern highbush blueberry, Fruit grow. and berry grow. in Rus. 32(2) (2012) 88-94.

[4] S.N. Reis, M.V. dos Reis, A.M.P. do Nascimento, Pandemic, social isolation and the importance of people-plant interaction, Ornam. Horticult. 26(3) (2020) 399-412.

[5] I.A. Trunov, Yu.V. Khoroshkova, Optimization of growth conditions of micro-plants of garden crops at the stage of adaptation, Bull. of Michurinsk State Agrar. Univ. 1(60) (2020) 90-97.

[6] I.A. Minakov, State regulation as a factor of innovative development of horticulture, Bull. of Michurinsk State Agrar. Univ. 2(61) (2020) 160166.

[7] K. Guravaiah, S. Raju, E-Agriculture: Irrigation System based on Weather Forecasting, in: Proc. of the IEEE 15th International Conference on Industrial and Information Systems (ICIIS), 2020, pp. 617-622.
[8] N. Kastornov, D. Tsyu, Modern state and trends in the development of horticulture, Bull. of Michurinsk State Agrar. Univ. 1 (2019) 136-138.

[9] Yu.V. Trunov, A.V. Soloviev, State and prospects of horticulture development in Russia. Technological features of modern gardening, Bull. of Michurinsk State Agrar. Univ. 3 (2012) 42.

[10] L.V. Grigoreva, Biological growth peculiarities of the cuttings of various rootstocks in a horizontal nursery, Int. J. of Pharmac. Res. 10(4) (2018) 632640.

[11] E.V. Avdeeva, V.F. Poletaikin, Green plants in environmental monitoring of the environment of the large industrial city, IOP Conf. Ser. Mater. Sci. and Engin. 822(1) (2020) 012008.

[12] I.A. Minakov, M.V. Azheurova, Strategy for the spatial development of horticulture of Russia, Bull. of Michurinsk State Agrar. Univ. 4(59) (2019) 135-140. 
[13] [9] A. Pnueli, In transition from global to modular temporal reasoning about programs, in: K.R. Apt (Ed.), Logics and Models of Concurrent Systems, Springer, Berlin, Heidelberg, 1984, pp. 123-144. DOI: https://doi.org/10.1007/978-3-642-82453-1_5

[14] [10] B. Meyer, Applying "Design by Contract", Computer 25(10) (1992) 40-51. DOI: https://doi.org/10.1109/2.161279

[15] [11] S. Bensalem, M. Bogza, A. Legay, T.H. Nguyen, J. Sifakis, R. Yan, Incremental component-based construction and verification using invariants, in: Proceedings of the Conference on Formal Methods in Computer Aided Design (FMCAD), IEEE Press, Piscataway, NJ, 2010, pp. 257-256.

[16] [12] H. Barringer, C.S. Pasareanu, D. Giannakopolou, Proof rules for automated compositional verification through learning, in Proc. of the 2nd International Workshop on Specification and Verification of Component Based Systems, 2003.

[17] [13] M.G. Bobaru, C.S. Pasareanu, D. Giannakopoulou, Automated assume-guarantee reasoning by abstraction refinement, in: A. Gupta, S. Malik (Eds.), Proceedings of the Computer Aided Verification, Springer, Berlin, Heidelberg, 2008, pp. 135-148. DOI: https://doi.org/10.1007/978-3-540-70545-1_14 